УДК 069

DOI: $10.32340 / 2514-772 X-2021-1-05-09$

Г. Н. Белоглазова

Средняя общеобразовательная школа № 125

с углубленным изучением отдельных предметов (Барнаул, Россия)

kasim60@mail.ru

\title{
РОЛЬ ШКОЛЬНОГО МУЗЕЯ В СОХРАНЕНИИ ИСТОРИЧЕСКОЙ ПАМЯТИ КАК ОДНОЙ ИЗ СОСТАВЛЯЩИХ КУЛЬТУРНОГО НАСЛЕДИЯ
}

\begin{abstract}
Аннотация. В статье рассматривается деятельность школьного музея, направленная на сохранение исторической памяти как одной из составляющих культурного наследия, на реализацию программ по патриотическому воспитанию, гражданскому и нравственному становлению молодёжи. Излагается история создания и развития школьного музея «Наследие», приводятся примеры деятельности музея, даётся описание мероприятий, описывается организация различной музейной деятельности среди учащихся.
\end{abstract}

Ключевые слова: школьный музей, наследие, сохранение культуры, молодёжь, патриотическое воспитание, нравственное становление, создание, развитие музея, музейная деятельность.

Культурное наследие сегодня - это прочно закрепившееся понятие в общественном и научном сознании. Это совокупность национальных культурных ценностей, научных открытий. Историческая память является одной из важных составляющих культурного наследия. Проблема сохранения исторической памяти народа одна из самых актуальных проблем нашего времени. Она важна для любой нации. Без знания истории большой и малой родины, деяний прошлых поколений, своих корней, рвётся нить, связующая эпохи, рушится преемственность поколений.

В последнее время в связи с многочисленными изменениями в социально-политической жизни России происходит смена общественных и личностных ценностей. Общество остро нуждается в гражданах с активной жизненной позицией, культурных, воспитанных людях. Деятельность, направленная на сохранение исторической памяти как одной из составляющих культурного наследия, необходима для успешной реализации программ по патриотическому воспитанию, гражданскому и нравственному становлению молодёжи.

Одними из хранителей исторической памяти и в прошлом и в настоящее время являются музеи различной типологии и классификации, библиотеки, архивы. Музеи образовательных учреждений также активно включены в этот важный процесс. Музей «Наследие». Музей «Наследие», созданный 29 октября 1998 года на базе Средней общеобразовательной школы № 125 города Барнаула по роду своей деятельности не является исключением. Создавался музей в сложное перестроечное время, когда ру- шились веками сложившиеся приоритеты и на их смену приходили новые. Существовала сложная ситуация в городе по количеству образовательных учреждений. На тот момент в школе № 125 практически в каждой возрастной параллели насчитывалось по 12-13 классов комплектов от буквы «А» до буквы «М». Учебный процесс в школе был организован в три смены. Но, не смотря на колоссальную загруженность, администрацией школы была изыскана возможность выделить небольшой кабинет для организации музейной комнаты. Директором школы на тот момент была Переладова Ольга Александровна.

Создание музея было инициировано педагогами школы. Стимулом и толчком стало проведение среди образовательных учреждений в Индустриальном районе города Барнаула выставки «Бабушкин сундук». Помимо изделий, изготовленных учащимися, на выставку следовало предоставить предметы прошлого, сделанные руками наших прабабушек и прадедушек - сокровища бабушкиного сундука. Именно при подготовке к выставке была собрана значительная коллекция старинных вещей, которая стала основой быстро растущего музея. Было разработано и утверждено на общем собрании педагогического коллектива «Положение о школьном музее», в программе развития были прописаны основные функции и направления деятельности музея. Приоритетными направлениями программы музея стали патриотическое воспитание и просветительная работа среди обучающихся. Через год музей уже располагался в просторном кабинете, была разработана концепция деятельности музея. 
Необходимо отметить, что с момента создания музея наблюдается стабильный рост количества музейных экспонатов основного и научного вспомогательного фонда.

В настоящее время целью деятельности школьного музея «Наследие» является создание условий для формирования чувств патриотизма, содействие формированию интереса к отечественной истории, сохранение исторической памяти народа, уважительного отношения к нравственным ценностям прошлых поколений, развитию коммуникативных компетенций, навыков исследовательской работы учащихся, поддержка творческих способностей детей $[1$, c. 1]. В поисково-исследовательской деятельности музея задействованы учащиеся 4-11 классов. Учащиеся по желанию принимают участие в работе музея и поисково-исследовательской деятельности. Несколько (обычно от двух до четырех человек) учащихся из каждого класса школы становятся помощниками музея. Учащиеся 2-4-х классов именуются «юными помощниками музея», учащиеся 5-11-х классов «следопыты музея».

Среди основных направлений работы музея:

- использование музейного материала для формирования позитивного отношения учащихся к активной социально-значимой деятельности через вовлечение их в активную деятельность музея;

- проектно-исследовательская деятельность на базе музея с привлечением экспонатов, музейных связей с ветеранами и их семьями;

- организация экскурсий в музей;

- организация работы с фондами музея (описание, регистрация в книгах ОФ (основной фонд) и НФ (научно-вспомогательный фонд);

- участие в городских, краевых мероприятиях исторической и краеведческой направленности;

- организация встреч с ветеранами, участниками Великой Отечественной войны, ветеранами труда, воинами интернационалистами, встреч, приуроченных к Дням воинской славы.

В музее ведёт свою работу Совет следопытов, разработаны задания по классам для коллективного обсуждения творческих общешкольных мероприятий, осуществляется формирование основного и вспомогательного фондов музея. При необходимости проводится посильно выполнимая реставрация музейного предмета (например - очистить от ржавчины кованые изделия, произвести ремонт экспонатов из текстиля и т. д.), подготавливается предмет к экспонированию в музейной выставке. В настоящее время практически каждый предмет, находящийся в музее, вовлекается в научную деятельность. Он исследуется, подбирается научный материал, связанный с историей создания и применения экспоната, благодаря изучению музейного экспоната происходит знакомство с историей города, а значит с историей страны.

Рассмотрим один из музейных экспонатов набор цветных карандашей 1947 года выпуска. Изучение данного экспоната позволило познакомиться с развитием карандашного дела в России. На основе изученного материала была разработана интерактивная экскурсия для младших школьников «Тайна коробки с карандашами». Во время экскурсии посетители музея знакомятся с историей появления экспоната в музее, легендой, связанной с простой невзрачной коробочкой с карандашами.

Проект «Барнаул вчера и сегодня». Идея проекта - напечатать и разместить в музее фотовыставку старинных фотографий старого Барнаула, выполненных в начале XX века фотографом С. И. Борисовым, в паре с современными фотографиями исторических объектов с ракурса, выбранного в далёком прошлом Борисовым. Одновременно с подготовкой выставки была разработана интерактивная экскурсия «Заглядывая в прошлое», которая позволяет совершить прогулку по историческим объектам, изображённым на фото, узнать их историю. Данная экскурсия пользуется популярностью у школьников, они в сопровождении экскурсовода из числа следопытов школьного музея «виртуально путешествуют» по старинным улицам города Барнаула.

В музее «Наследие» собрана коллекция старинных ёлочных игрушек. При создании новогодней выставки в музее она ежегодно становится радостным событием для малышей, когда они приходят посмотреть в музей выставку и поучаствовать в интерактивном музейном мероприятии «Приключение ёлки в России».

Разработанная руководителем музея программа деятельности музея «Наследие» [2] направлена на приобщение учащихся к традиционным ценностям, вовлечение их в проектноисследовательскую деятельность. В музее ведётся большая работа по национальному и военно-патриотическому воспитанию молодежи.

Так, в 2019-2020 учебном году под руководством руководителя музея «Наследие» и обучающимися в объединении «Родословие» был разработан проект «Душа солдата в письмах дышит», целью которого стало привлечение 


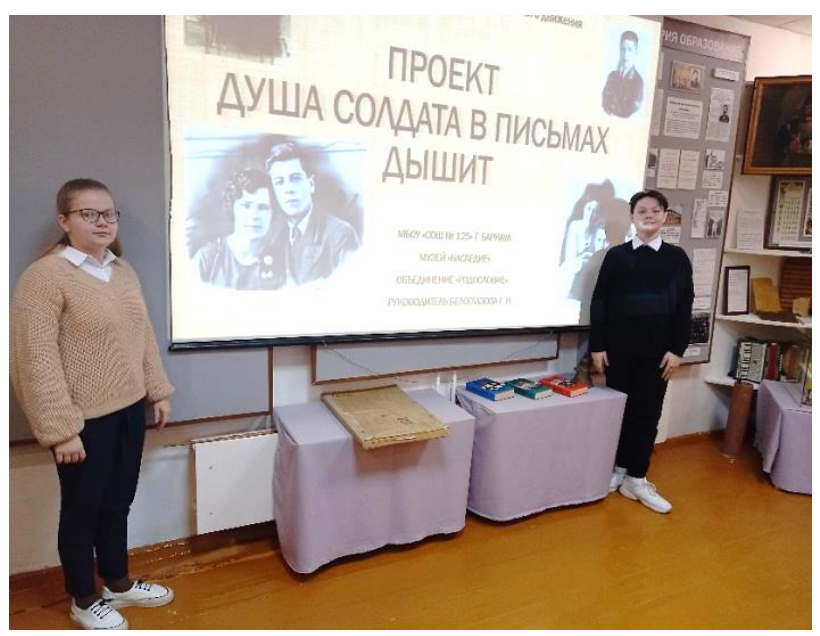

Рис. 1. Музейное мероприятие.

На фото Любивая Злата, Кокорин Захар

внимания учащихся к проблеме сохранения памяти о Великой Отечественной войне. Благодаря данному проекту вновь была перелистана история земляков, участников Великой Отечественной войны. Благодаря письмам с фронта из сборника «Письма с фронта любимым» [3] было создано 25 коротких зарисовок и смонтированы клипы 18 авторов писем с фронта на Алтай. В процессе подготовки проекта ребята самостоятельно выбирали авторов писем и тексты, которые были прочитаны на фоне музыки и слайдовой презентации из фотографий военных лет. Данная работа была представлена на конкурс и в настоящее время используется при проведении классных часов и экскурсий в музее [4].

Направление, выбранное в музее для исследовательской деятельности обучающихся - краеведческое, делится на два вида: групповое и индивидуальное. Следопыты-исследователи изучают семейные архивы, анализируют литературу по исследуемой теме, проводят опросы, интервьюирование среди своих родных. Интервьюирование позволяет пополнять фонд устной истории музея. Материалы фонда устной истории используются для написания рефератов, для подготовки выставок и экскурсий. С исследовательскими работами учащиеся участвуют в конкурсах муниципального, регионального и Всероссийского уровня и становятся победителя и призёрами. Для получения информации составляются вопросы по определённой теме, и проводится интервьюирование.

- участие жителей края в Великой Отечественной войне;

- дети войны;

- истории, связанные с историческими личностями, проживающчими на Алтае и т. $n$.
В частности, в год празднования юбилея нашего земляка Ильи Шумакова [5] члены экскурсионной группы провели на улице Шумакова (г. Барнаул, Алтайский край) опрос, включавший в себя два вопроса: «Кто такой Илья Шумаков? Какой он совершил подвиг, что его именем названа улица?» Из прохожих никто не дал правильного ответа на поставленный вопрос. В ходе опроса прохожим, с которыми беседовали следопыты музея, были вручены буклеты с краткой информацией о деятельности Ильи Шумакова. Необходимо отметить, что информация, связанная с подобной исследовательской деятельностью музея, регулярно размещается на сайте школы и музея. В данном случае музей выступает проводником исторических знаний.

В связи с тем, что большую роль в формировании гражданского самосознания играет сохранение исторической памяти поколений, в музее проводятся музейно-тематические мероприятия, посвящённые историческим событиям нашей страны. Например, такие, как 800-летие со дня рождения Александра Невского. Гостями данного мероприятия были ветераны Индустриального территориального общественного самоуправления, отец Иоанн, священник храма Иоанна Богослова (г. Барнаул), учащиеся школы, следопыты музея «Наследие». Музейное мероприятие, благодаря демократичному формату, получилось интересным, прошло в непринуждённой обстановке, учащиеся задавали массу вопросов гостям и получили на них исчерпывающие ответы.

Любое музейное мероприятие призвано сохранять историческую память, которая служит для объединения человека с его предками. Изучение родословия способствует возрождению ценности семьи, семейных отношений в духовно-эмоциональной связи поколений. Прошлое сходно с корнями, которые держат и питают дерево. Если лишить его корней, дерево погибнет. Потеря человечеством его исторического прошлого приведет к его к утрате национальной идентичности. Основополагающая задача кружка «Родословие», который ведёт свою деятельность при музее «Наследие», создать условия для формирования у учащихся бережного отношения к прошлому своих предков. Кружковцы занимаются написанием родословия своей семьи, составляют родовое древо, ведут поиск информации о своих прадедах, их героическом прошлом. Кроме того, они исследуют ресурсы Интернета, электронный банк данных о советских воинах (погибших, умерших от ран во время Великой Отечественной войны), обраща- 
ются за информацией к сайту, посвященному памяти жертв ГУЛАГа. Изучают документы из семейных и государственных архивов, беседуют с родственниками, описывают полученный материал. Найденная информация позволяет грамотно составить родословную своей семьи, помогает построить схемы семейного генеалогического древа, презентабельно представить полученный материал истории своего рода [6].

Собрание подлинных музейных артефактов способствует передаче накопленного культурного опыта от поколения к поколению, позволяет хранить память о вечных ценностях, память о подвигах и воинской славе, о героических страницах Великой Отечественной войны. Фото, награды, документы, личные вещи ветеранов времен Великой Отечественной войны и воинов-интернационалистов представлены в музее на стендах и в витринах экспозиции на выставке «По дорогам войны». Собранные следопытами музея, подаренные посетителями экспонаты, вводятся в научный оборот, исследуются. Полученная информация используется для написания рефератов - результата изысканий юных музейщиков, которые затем апробируются на конференциях различного уровня. Кроме того, полученные материалы используются для проведения тематических классных часов в музее, информация о проводимых мероприятиях в музее размещается на сайте школы [7], предоставляется материал для публикации в местных средствах массовой информации.

Музей «Наследие» активно сотрудничает с музеями высших учебных заведений, муниципальными и государственными музеями края, музеями образовательных учреждений, Государственным архивом Алтайского края, общественными организациями. Сотрудничество заключается в организации совместно проводимых музейно-тематических мероприятий, выставок, музейных проектов. Помимо традиционной экспозиционной, выставочной, научноисследовательской деятельности, популяризации исторического и культурного наследия края через проведение экскурсий, организации музейно-тематических мероприятий активно используются современные способы представления информации - создание аудиогида по экспозициям в музее. Аудиогид привлекателен для подрастающего поколения, позволяет получать историческую информацию.

Кружковцами была создана аудиоэкскурсия, посвящённая истории школы середины XX века. На страницах аудиогида, размещённых на сайте школы [7] представлены фото и описание школьных принадлежностей ученика, обучаю-

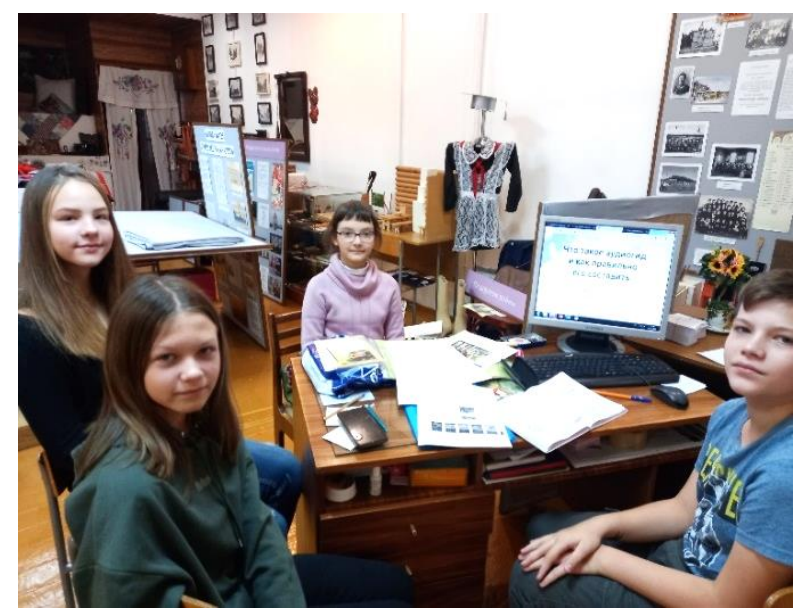

Рис. 2. Кружковцы во время создания Аудиогида

щегося в школе в 50-60-х годах прошлого столетия. Даётся представление о детских организациях того времени, школьных традициях. Данная деятельность продолжается, активисты музея работают над созданием аудиогида выставок и экспозиций, находящихся в музее «Наследие».

Роль школьного музея в сохранении и трансляции исторической памяти и культурного наследия очевидна. Историческая память является одной из важных составляющих культурного наследия. Посредством музея создается обратная связь между учеником и учителем, классом и классным руководителем, музей становится проводником положительного опыта сохранения исторической памяти, культурного наследия, способствует объединению народа, возрождению и сохранению семейных традиций, является местом сохранения культурного наследия для передачи его будущим поколениям.

\section{Список литературы}

1. Анализ деятельности музея «Наследие» за 2020-2021 учебный год. Научновспомогательный фонд музея «Наследие» МБОУ «СОШ № 125», 2021.4 c.

2. Программа деятельности музея «Наследие» МБОУ «СОШ № 125» города Барнаула Алтайского края 2020-2025 гг. Научновспомогательный фонд музея «Наследие» МБОУ «СОШ № 125».

3 . Белоглазова $Г$. Н. Письма с фронта любимым. Барнаул, Новосибирск, 2020. 496 с.

4. Проект «Душа солдата в письмах dыıшит». URL: http://doocaltai.ru/dusha_soldata. $\mathrm{html}(24.02 .2021)$.

5. «Исторические личности Алтайского края», музей "Наследие», папка фото «Илья Шумаков». Научно-вспомогательный фонд музея «Наследие» МБОУ «СОШ № 125». 


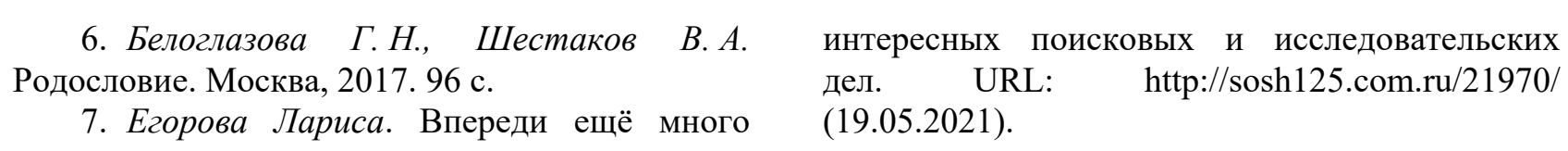

УДК 37.013:159.924.24

DOI: $10.32340 / 2514-772 X-2021-1-09-12$

И. Л. Борзенко, кандидат педагогических наук Алтайский государственный институт культуры (Барнаул, Россия) irinab77@yandex.ru

Л. А. Комаристая, кандидат исторических наук, доцент Алтайский государственный институт культуры (Барнаул, Россия) super.humanity2015@yandex.ru

3. Н. Лукьянова,
кандидат психологических наук, профессор
Алтайский государственный институт культуры (Барнаул, Россия)
lukyanova1948@inbox.ru

\section{ПРЕЕМСТВЕННАЯ СВЯЗЬ ГУМАНИТАРНОГО ЗНАНИЯ И РАЗВИТИЯ ТВОРЧЕСКИХ СПОСОБНОСТЕЙ (К ПОСТАНОВКЕ ПРОБЛЕМЫ)}

Аннотация. В работе рассматриваются проблемы формирования личности методом её участия в творческой деятельности. Поднимается проблема определения способов влияния гуманитарного знания на развитие личности. Анализируется роль гуманитарных дисциплин в развитии интереса к творческой деятельности, а также поднимается проблема обратного влияния участия в этой деятельности на проявление интереса к учебным дисциплинам гуманитарного цикла, побуждения нового осмысления их содержания.

Ключевые слова: гуманитарное знание, творческая деятельность, личность, преемственность, культура, способности.

В современном образовании важным направлением его развития является переход на новые образовательные стандарты. Их задача - это создание такой социальнопедагогической среды, которая поможет в формировании и развитии обучающихся, в реализации своих проектов и инициатив. Сегодня важнейшим приоритетом образования выступает обеспечение качества образования. А чтобы оно было качественным, нужны специально созданные условия. И одним из таких условий является непрерывность образования. До недавнего времени в практике образования речь шла о преемственности обучения, сегодня это понятие трансформировалось в преемственность образования. Это то, что как раз и создает непрерывный образовательный процесс. Преемственность в образовании может проявляться во взаимодействии задач, содержания, методов и технологий обучения и воспитания. В своей статье мы остановимся на преемствен- ности, которая проявляется во взаимосвязи гуманитарного знания и развития творческих способностей.

Проблема преемственности обучения школьного, досугового, средне-специального и других, разрабатывалась в психологопедагогической науке ещё в прошлом столетии. С. Л. Рубинштейн говорил о необходимости учёта в овладении знаниями собственной деятельности ребёнка, его актуализации своего познавательного опыта. Он утверждал: «Всякая попытка воспитателя-учителя «внести» в ребёнка познание и нравственные нормы, минуя собственную деятельность ребёнка по овладению ими, подрывает... самые основы здорового умственного и нравственного развития ребёнка, воспитания его личностных свойств и качеств» $[1$, c. 192-193]. В этом отношении важна роль житейского опыта, даже если он невелик.

Авторы более позднего времени Ю. В. Сенько, В. Э. Тамарин и другие [2] гово- 